\title{
Conventional and complementary health care use and out-of-pocket expenses among Australians with a self-reported mental health diagnosis: a cross-sectional survey
}

Erica McIntyre ${ }^{1,2^{*}}$, Tracey Oorschot ${ }^{1}$, Amie Steel ${ }^{1}$, Matthew J Leach ${ }^{1,3}$, Jon Adams ${ }^{1}$ and Joanna Harnett ${ }^{1,4}$

\begin{abstract}
Background: Mental health disorders are a global health concern. In Australia, numerous national reports have found that the current mental healthcare system does not adequately meet the needs of Australians with mental illness. Consequently, a greater understanding of how people with a mental health disorder are using the broader healthcare system is needed. The aim of this paper is to explore conventional and complementary health care use and expenditure among Australian adults reporting a mental health disorder diagnosis.

Methods: A cross-sectional online survey of 2,019 Australian adults examined socio-demographic characteristics, complementary and conventional health care use and the health status of participants.

Results: $32 \%(n=641)$ of the total sample $(N=2019)$ reported a mental health disorder in the previous 3 years. Of these, $96 \%$ reported consulting a general practitioner, $90.6 \%$ reported using prescription medicines, $42.4 \%$ consulted a complementary medicine practitioner, $56.9 \%$ used a complementary medicine product and $23 \%$ used a complementary medicine practice. The estimated 12-month out-of-pocket health care expenditure among Australians with a mental health disorder was AUD\$4,568,267,421 (US\$3,398,293,672) for conventional health care practitioners and medicines, and AUD\$1,183,752,486 (US\$ 880,729,891) for complementary medicine practitioners, products and practices. Older people (50-59 and 60 and over) were less likely to consult a CM practitioner $(O R=$ $0.538,95 \% \mathrm{Cl}[0.373,0.775] ; O R=0.398,95 \% \mathrm{Cl}[0.273,0.581]$ respectively) or a psychologist/counsellor ( $O R=0.394$, $95 \% \mathrm{Cl}[0.243,0.639] ; \mathrm{O}=0.267,95 \% \mathrm{Cl}[0.160,0.447]$ respectively). People either looking for work or not in the workforce were less likely to visit a CM practitioner $(O R=0.298,95 \% \mathrm{Cl}[0.194,0.458]$; $O R=0.476,95 \% \mathrm{Cl}[0.353$, $0.642]$, respectively).
\end{abstract}

\footnotetext{
* Correspondence: erica.mcintyre@uts.edu.au

${ }^{1}$ Australian Research Centre in Complementary and Integrative Medicine, School of Public Health, Faculty of Health, University of Technology Sydney, 2007 Ultimo, NSW, Australia

${ }^{2}$ Institute for Sustainable Futures, University of Technology Sydney, PO Box 123, 2007 Ultimo, NSW, Australia

Full list of author information is available at the end of the article
}

C C The Author(s). 2021 Open Access This article is licensed under a Creative Commons Attribution 4.0 International License, which permits use, sharing, adaptation, distribution and reproduction in any medium or format, as long as you give appropriate credit to the original author(s) and the source, provide a link to the Creative Commons licence, and indicate if changes were made. The images or other third party material in this article are included in the article's Creative Commons licence, unless indicated otherwise in a credit line to the material. If material is not included in the article's Creative Commons licence and your intended use is not permitted by statutory regulation or exceeds the permitted use, you will need to obtain permission directly from the copyright holder. To view a copy of this licence, visit http://creativecommons.org/licenses/by/4.0/. The Creative Commons Public Domain Dedication waiver (http://creativecommons.org/publicdomain/zero/1.0/) applies to the data made available in this article, unless otherwise stated in a credit line to the data. 
Conclusions: A substantial proportion of Australian adults living with a mental health disorder pay for both complementary and conventional health care directly out-of-pocket. This finding suggests improved coordination of healthcare services is needed for individuals living with a mental health disorder. Research examining the redesign of primary health care provision should also consider whether complementary medicine practitioners and/ or integrative health care service delivery models could play a role in addressing risks associated with complementary medicine use and the unmet needs of people living with a mental health disorder.

Keywords: Mental Health, Health Services, Health Care expenses, Complementary medicine, Survey

\section{Background}

Mental health disorders (MHD) are a global health concern, with as many as one in three people worldwide, and one in five Australians, reporting a common MHD (depression, anxiety or substance use disorder) in the past 12 months $[1,2]$. These disorders are one of the largest contributors of global disease burden, representing $32 \%$ of years lived with disability from all causes [3]. In addition, mental health disorders are associated with lower social and economic participation, diminished physical health and subsequent chronic illness, lower standards of living and premature death [4]. Economic costs, particularly out-of-pocket (OOP) costs, further contribute to the burden of mental illness by increasing financial pressures, which in turn, contribute to health inequities $[5,6]$.

Despite the considerable burden of MHD, there has been little evidence of improvement in mental health outcomes in many countries, including Australia [4]. The Australian Productivity Commission's (APC) Inquiry Report [4] recognises that the current mental health care system does not adequately meet the needs of Australians with mental illness and has called for substantial reforms to drive significant change in how mental ill-health is understood and treated. These unmet health needs may, in part, drive many people with mental health problems to use a variety of health care services and interventions [4, 7], including complementary medicine $(\mathrm{CM})$ services, products and practices that are not considered part of mainstream health care [7-9]. Previous research has revealed that almost $75 \%$ of Australian adults experiencing anxiety report using herbal medicines (a type of CM product) in their lifetime, with relatively fewer $(55 \%)$ using prescribed medications [10]. In people with depressive disorders, it is estimated that up to $30 \%$ of adults use CM [9].

Given the high rates of $\mathrm{CM}$ use among people living with mental illness, it is not surprising that OOP costs related to $\mathrm{CM}$ use have been shown to be higher than that reported for conventional pharmaceutical use [6]. A recent whitepaper by Zurich Australia [11] estimated individual OOP costs specific to mental health care to be close to AUD\$ 1,350 (US\$ 1,004) per annum. Consistent with mental health care expenditure in general, OOP costs are continuing to rise, which may result in substandard care or avoidance of care-both contributing to poor mental health outcomes $[5,11]$. As these estimates are limited to conventional health care use, it is likely that OOP costs will be substantially greater when $\mathrm{CM}$ use is taken into account.

The multiple factors influencing mental health outcomes, discussed above, have important policy implications. In fact, Spinks and Hollingsworth [6] have called for government action to integrate CM-related issues into policy, not dissimilar to policies concerning conventional health care use. The reasons for this call for action are clear. CM users with mental illness are more inclined to self-treat and less likely to seek professional treatment [6]. In addition, concurrent $\mathrm{CM}$ and conventional medicine use [6,7], combined with non-disclosure and poor health literacy, creates myriad health risks (e.g., delayed, inappropriate or harmful treatment) that are yet to be meaningfully addressed at the policy level $[6,7,12]$.

To address policy gaps pertinent to health care use and their impacts, it is imperative to understand how people with a MHD use health services, products and practices. Alarmingly, there has not been an investigation of conventional and CM health care use in adults with a MHD in Australia in over a decade. This study addresses this knowledge gap by examining conventional and CM health care use, including OOP costs, among Australian adults reporting a MHD as well as exploring the sociodemographic and health-related characteristics of health service users, and the prevalence and predictors of health care use in this population.

\section{Methods}

\section{Study design}

National cross-sectional survey.

\section{Setting and participants}

This study used a sample $(N=2,025)$ principally representative of the Australian population with regards to age, gender and state/territory of residence as indicated by Australian Bureau[13] of Statistics data [14]. For a comparison between this sample and the national population data see Steel et al. [13]. Employing a crosssectional design, the reported results drew from a sub- 
study analysis of a wider project. Data collection and recruitment was conducted between 26 July and 28 August 2017, by contacting registered participants of Qualtrics (an online platform used for research participant recruitment).

Adopting a purposive convenience sampling method, eligible Australian participants aged 18 years and over, were contacted by email $(N=41,000)$ and instructed to use the weblink provided to obtain further information about the study. The response rate was $5 \%$. Respondents indicating an interest to participate were asked to provide consent prior to commencing the online survey. All respondents who completed the survey confirmed their informed consent. The completion time of the survey was approximately $15 \mathrm{~min}$. Reflecting the financial incentive scheme of registered Qualtrics members, a small financial reward was offered to participants who completed the survey.

\section{Measures}

The 50-item survey included questions concerning sociodemographic characteristics, health care use and health status. Using a convenience sample of seven Australian adults, the survey items were tested with respect to response option suitability, question construction and ease of use. Respondent feedback resulted in minor changes to the questionnaire.

\section{Health status}

Participants were asked if they had been diagnosed with any health conditions within the last 3 years (yes/no) from a list of chronic health conditions, including the following mental health diagnoses: mood disorder (e.g., depression), anxiety disorder, sleep disorder, substance use disorder, schizophrenia or other psychotic disorder, or other mental health disorder.

\section{Health care use}

Participants were asked about their conventional health care use within the last 12 months including consultation with a primary care physician, allied health worker (e.g., counsellor), medical specialist, or hospital-based health care professional (e.g., hospital doctor). The 20item Short Form Health Survey (SF-20) was used to assess health related quality of life across six dimensions of health: physical functioning, role functioning, social functioning, mental health (MHI-5), current health perceptions, and pain [15]. The five items comprising the MHI-5 measure the frequency of general mental health symptoms in the previous month on a 6-point scale $(1=$ All of the time to $6=$ None of the time), with higher summed scores indicating better mental health. Participants were also asked to report consultation frequency, reason for consultation and estimated OOP costs.

$\mathrm{CM}$ use was measured using items from the validated International Complementary and Alternative Medicine Questionnaire (I-CAM-Q) [16, 17]. As the I-CAM-Q requires country specific adaptation [18], some changes were made to reflect Australian cultural contexts. Participants were asked about their CM usage within the last 12 months with respect to $\mathrm{CM}$ products, mind-body practices and consultations with $\mathrm{CM}$ practitioners. Reasons for these consultations and estimated OOP costs were also solicited.

\section{Data analysis}

IBM SPSS Statistics Premium Edition Version 25 (Armonk, New York, IBM Corp) was used to analyse the data. Prior to conducting analyses, raw data were screened for any missing or incomplete responses. During this process, six cases were removed as the data were deemed unreliable; this included text responses that were incongruous with the corresponding question, repeated patterns throughout the data, and inconsistency in responses. After removal of the six cases, 2,019 cases were included in the final data set. Binary variables were created from categorical variables that related to $\mathrm{CM}$ use, as well as diagnosed illnesses. Mental health diagnoses were categorised into four groups for analysis: any MHD, anxiety disorder, mood disorder, and other MHD (all excluding anxiety and mood). The total summed score of the MHI-5 items was transformed a standard score from to 0 to 100 . Descriptive statistics were used to determine the percentages and frequencies. Chisquare analysis was used to assess associations between categorical sociodemographic and health-related variables. Cramer's V was used to measure the magnitude of these associations. Independent $t$-tests were used to determine differences between groups for continuous variables; the Welch t-test was used if the homogeneity of variance assumption was violated according to Levene's test $(p>.05)$. Covariates were included in regression analyses if they were theoretically relevant or had an association $p<.25$ [19]. Logistic regression was used to identify predictors of health care use. Hierarchical multiple regression was used to predict total health care expenditure from MHD. Statistical significance was set to $p<.05$.

Participants' mean OOP expenditure for health services and medicines-inclusive of $\mathrm{CM}$ and conventional health-was used for the economic analysis. As the economic data were not normally distributed, MannWhitney $\mathrm{U}$ tests were used to determine the median differences in OOP expenses (continuous variable) between those with and without a MHD (categorical variable). Population level OOP expenditure was calculated for the 
estimated number of the Australian population with a MHD_determined based on the prevalence of MHD reported in this study multiplied by the number of Australian adults aged 20 years or above $(n=17,615$, 676) reported in Australian census figures for 2016 [20]. Data for the number of Australian adults 18 to 19 years was not available. The estimated total expenditure by Australian population with a MHD was then extrapolated by multiplying the reported mean expenditure by MHD participants in this study by the estimated number of Australians with a MHD. Expenses are reported in Australian dollars.

\section{Ethics}

The Human Research Ethics Committee at Endeavour College of Natural Health provided ethics approval $(20,170,242)$ in accordance with the National Health and Medical Research Council Statement on Ethical Conduct in Human Research. Charles Sturt University (H17048), The University of Sydney (2017/140) and The University of Technology Sydney (ETH17-1564) Human Research Ethics Committees also granted ethics approval.

\section{Results}

$32 \%(n=641)$ of the total sample $(N=2019)$ reported a MHD in the previous 3 years. Of these, $20 \%(n=402)$ reported an anxiety disorder, $19 \%(n=387)$ a mood disorder and $18 \%(n=372)$ at least one other MHD. The general mental health status for the total sample $(M=63.63, S D=22.98)$ was slightly lower than previously reported general population means [21]. The mental health status of those reporting a mood disorder $(M=42.94, S D=$ $20.54)$, anxiety disorder $(M=42.97, S D=20.82)$ or other MHD $(M=46.04, S D=22.47)$ was consistent with clinical population norms [22].

\section{Sociodemographic characteristics}

Table 1 presents the descriptive statistics for the participants sociodemographic characteristics and their association with each category of MHD (i.e., any MHD, anxiety disorder, mood disorder, and other MHD). As detailed in Table 1 , there were statistically significant associations $(p<.05)$ between gender, employment status, marital status, educational qualification, financial manageability, health care card or private health insurance and all MHD categories. The magnitude of these associations were mostly small, with Cramer's $\mathrm{V}$ values ranging between 0.06 and 0.25 . Those who were female (compared to males), not in the paid workforce (compared to those in the workforce), never married (compared to those who are or have been married), or had a vocational qualification (compared to those with an education level at or below year 12) more frequently reported all MHD categories. Participants with a health care card, compared to those without, reported all categories of MHD less frequently. In contrast, those who found financial management difficult some or all of the time (compared to those finding it not too bad or easy) and those with private health insurance (compared to those without) more frequently reported all categories of MHD.

Age and remoteness of residence was significantly associated $(p<.05)$ with having either any mental health disorder, anxiety or a mood disorder, but not with having any other mental health disorder (not anxiety or mood). Participants who were 60 years and over reported any of these diagnoses less frequently than all other age groups. Compared to those living in outer regional/remote areas, participants living in a major city or inner regional area more frequently reported having any MHD.

\section{Health related characteristics}

Table 2 summarises the results of Chi-square tests of association between MHD, physical health diagnosis and number of chronic conditions. Each category of MHD had large significant associations $(p<.01)$ with each comparable MHD category (Cramer's $\mathrm{V}$ between 0.45 and 0.58). Participants reporting an anxiety disorder, compared to those without, were more likely to have either a mood disorder diagnosis or any other MHD. Similarly, compared to participants without a mood disorder, those reporting a mood disorder diagnosis were more likely to have any other MHD.

A physical health diagnosis of a cardiovascular, female reproductive, gastrointestinal, musculoskeletal or respiratory condition were all statistically significantly associated with each category of MHD $(p<.05)$. However, the strength of the associations varied according to the specific category of physical illness diagnosis and MHD. For example, the association between musculoskeletal conditions and anxiety disorders was negligible (Cramer's $\mathrm{V}=0.06$ ), compared to a moderate association between gastrointestinal disorders and any MHD (Cramer's V $=0.23$ ). Participants reporting each of these physical conditions were more likely to report any MHD, anxiety or mood disorder, compared to those without each condition.

Participants with a diabetes diagnosis were more likely to report having any MHD or other MHD, although the association was of negligible significance $(p=.006$, Cramer's V $=0.06$ ). Participants reporting other physical illnesses were significantly $(p>.01)$ more likely to report a mood disorder, although the association was negligible (Cramer's V $=0.06$ ).

Number of chronic conditions had large significant associations with all categories of MHD $(p>.001$, Cramer's $\mathrm{V}$ between 0.55 and 0.67 ). People with five or more 


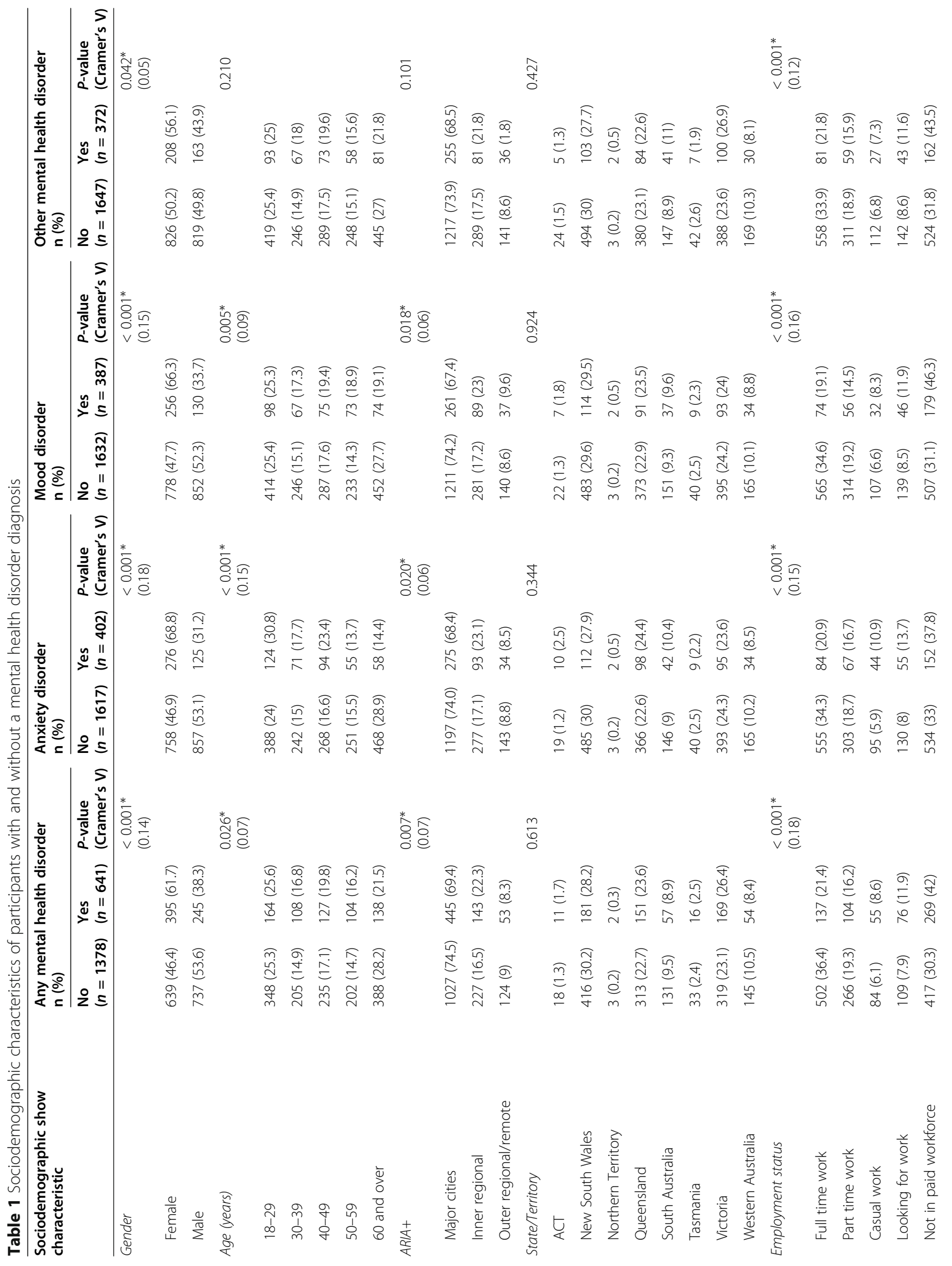




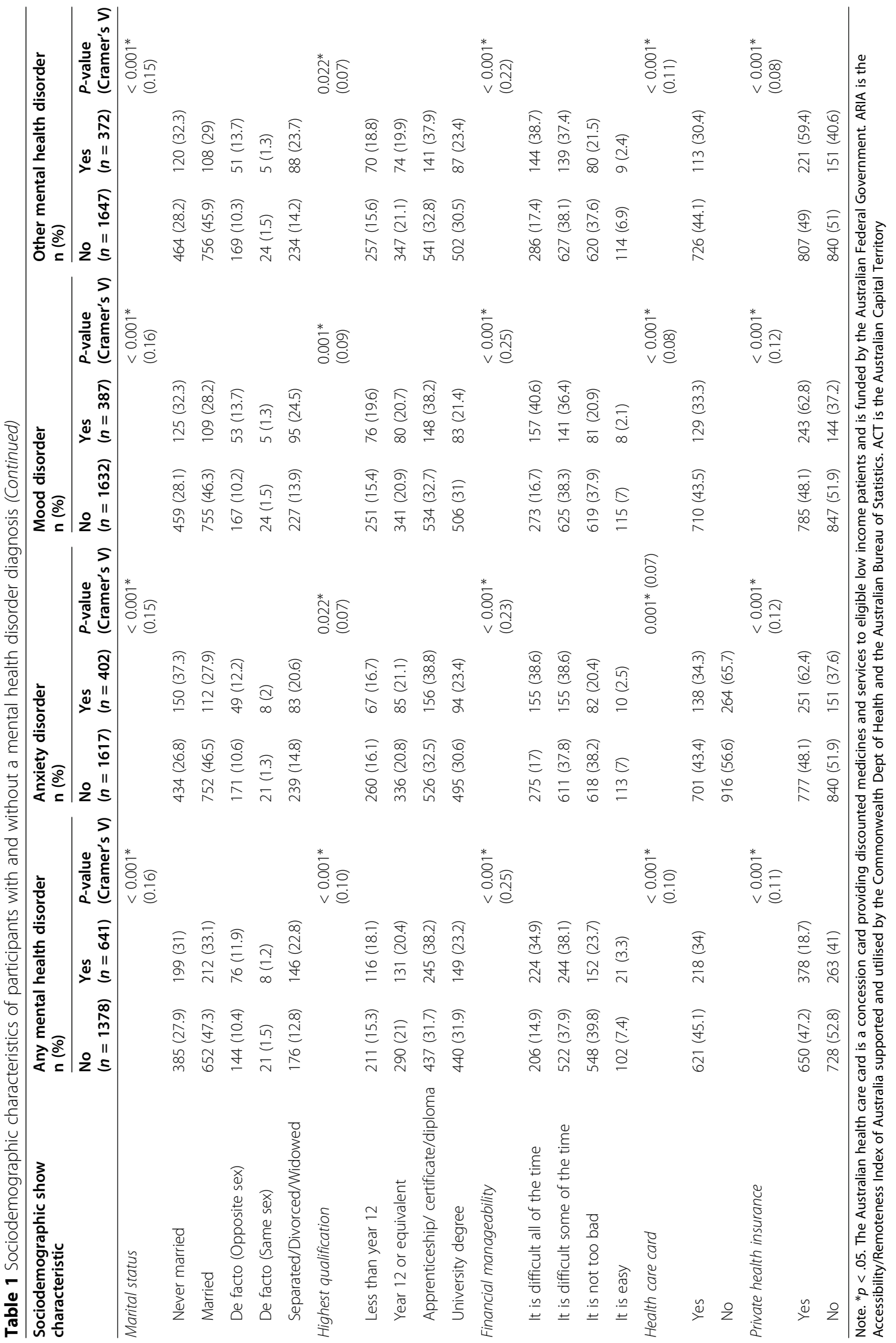




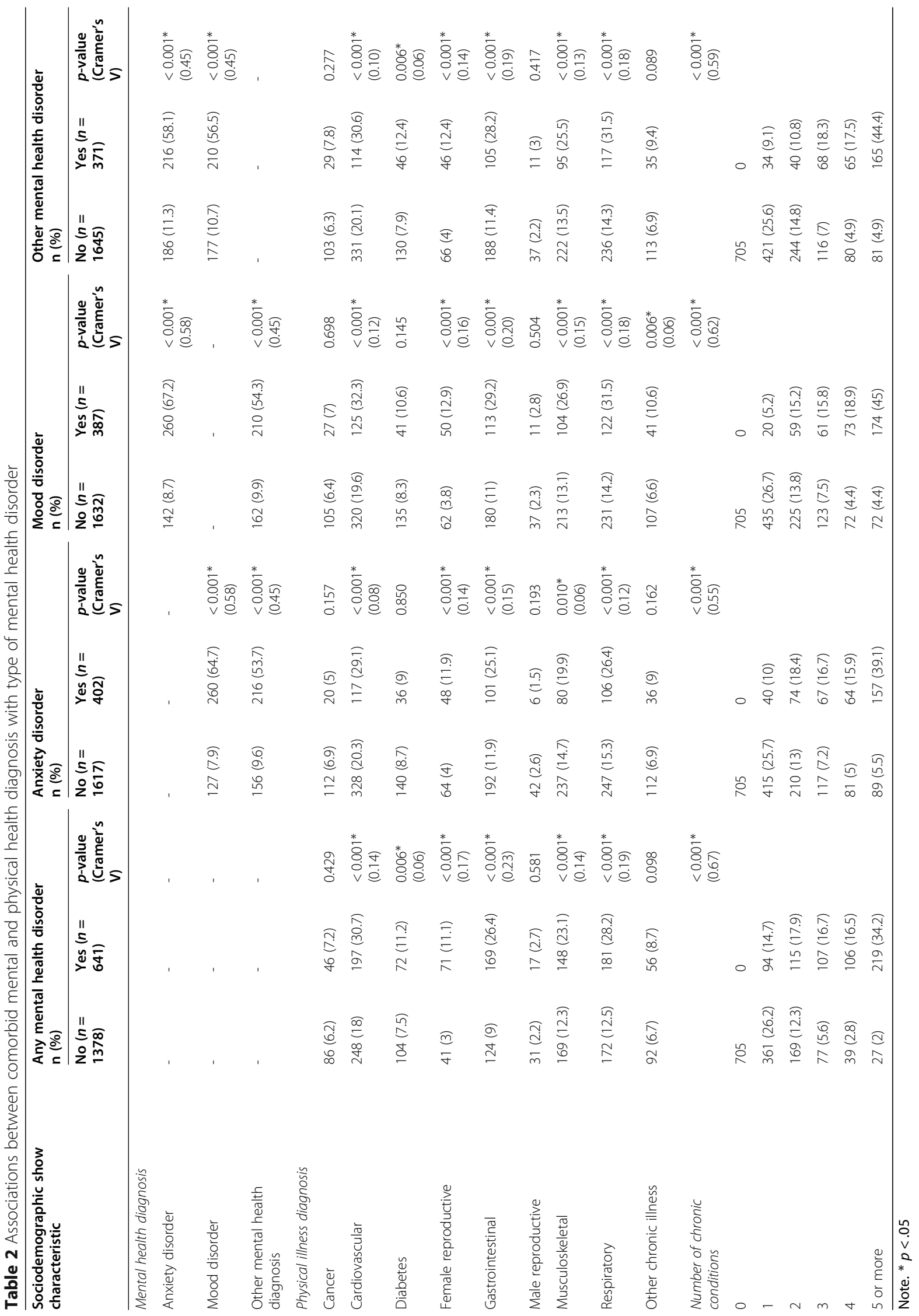


illnesses had the highest reported rates of all MHD categories, including any mental health disorder $(34.2 \%)$, anxiety $(39.1 \%)$, mood $(45 \%)$ or other MHD (44.4\%).

\section{Prevalence of conventional and complementary health care use}

All forms of conventional health care use (i.e., medical doctor, allied health and pharmaceuticals) were significantly associated with each MHD category $(p<.001)$; with the strength of associations ranging between negligible (Cramer's V $=0.05$ for physiotherapist and mood disorder) to large (Cramer's $\mathrm{V}=0.46$ for psychologist/ counsellor and any MHD). Within the medical doctor category, participants most frequently consulted a general practitioner for all categories of MHD (over 96\%), followed by hospital doctors, who were consulted by between 41.8 and $47.3 \%$ of participants. Within the allied health category, most people consulted a pharmacist across all types of MHD (88-89.9\%), with the lowest consultation rates reported for community nurses (15.6 to $19.9 \%)$. The highest use of pharmaceutical medicines related to prescription use across all MHD categories, including any mental health disorder $(90.6 \%)$, anxiety (92\%), mood (92.8\%) and other (91.1\%). See Table 3 for summary statistics.

Complementary health care use was categorised as: $\mathrm{CM}$ practitioner consultations, and CM products and practices (i.e., non-ingestible treatments such as massage therapies, yoga and Tai Chi). Consulting with any CM practitioner in the previous 12 months was significantly associated with each MHD category $(p<.001)$. The significance and strength of associations for each type of CM practitioner varied across MHD categories (see Table 3). The largest proportion of participants consulted a massage therapist for any MHD (23.9\%), anxiety $(24.4 \%)$ and other MHD (25.5\%). In contrast, homeopaths were consulted the least for any MHD $(4.5 \%)$, anxiety $(4.2 \%)$ and mood (4.2\%) disorder, and acupuncturists consulted the least for other MHD $(2.2 \%)$. There were no statistically significant associations between any specific type of CM practitioner and people reporting a mood disorder diagnosis.

Use of CM practice or product was significantly associated with all MHD categories $(p<.05)$. The significance and strength of associations, and the prevalence of use, for each type of CM practice or product varied by MHD category (see Table 3). Vitamin or mineral supplements had the highest usage rates across all MHD, including any MHD (54.9\%), anxiety (54.7\%), mood (53.5\%), and other MHD (54.6\%). Relaxation techniques had the highest prevalence of use of the CM practices, which were used by $21.4-23.7 \%$ of participants across all MHD categories.

\section{Out-of-pocket expenditure}

On average in the previous 12 months, the total self-reported OOP expenditure on health care by each participant with a MHD was AUD\$ 1030.06 (US\$ 767.12). This extrapolated to estimated OOP costs of AUD\$ 5,752,019,906 (US\$ 4,284,028,624) for health care used by adults with a MHD in Australia $(n=5,584,169)$ with AUD\$ 4,568,267,421 (US\$ 3,398,293,672) for conventional health care practitioners and medicines, and AUD $\$ 1,183,752,486$ (US\$ 880,729,891) for complementary medicine practitioners, products and practices.

The OOP expenditure on each type of health service and treatment in the previous 12 months is reported in Table 4. Participants with a MHD, compared to those without, spent significantly more on both over-thecounter (OTC) pharmaceutical medicines $(U=377,595$, $z=4.01, \quad p<.000)$ and prescription medicines ( $U=$ $404,783, z=6.76, p<.000)$. For those consulting with conventional health practitioners, those with a MHD spent significantly more than those without a MHD on specialist doctors $(U=424,837, z=5.89, p<.000)$, hospital doctors $(U=389,032, z=2.97, p<.000)$ and counsellors/psychologists $(U=428,171, z=9.41, p<.000)$.

For those consulting with a CM practitioner, a significant difference in expenses was only found for participants consulting with a naturopath; those with a MHD spent significantly more on consultations than those without a MHD, $U=66,122, z=2.53, p=.01$. For those who used CM products, participants with a MHD spent significantly less on yoga, Tai Chi or Qi Gong compared to those without a diagnosis, $U=14,319, z=-2.86$, $p<.000$. There was no significant difference in median expenditure on each type of CM product between participants with or without a MHD.

Table 5 presents the results of the hierarchical multiple regression predicting total health care expenses from MHD diagnosis. The full model including relevant sociodemographic variables, chronic physical illness and MHD (Model 3) was statistically significant $\left(R^{2}=0.038\right.$, $F(11,2001)=7.111, p<.0001$, adjusted $\left.R^{2}=0.033\right)$; accounting for less than $4 \%$ of the variance in total health care expenditure. Employment status, private health insurance, chronic physical illness and MHD were all significant predictors of total health care expenses in the final model.

\section{Predictors of type of health practitioner use}

The logistic regression models predicting each type of health practitioner visited were statistically significant $(p<.001$; see Table 6). Gender, employment status, financial management, private health insurance, health care card, MHD and chronic physical illness diagnosis were all significant predictors of general practitioner 


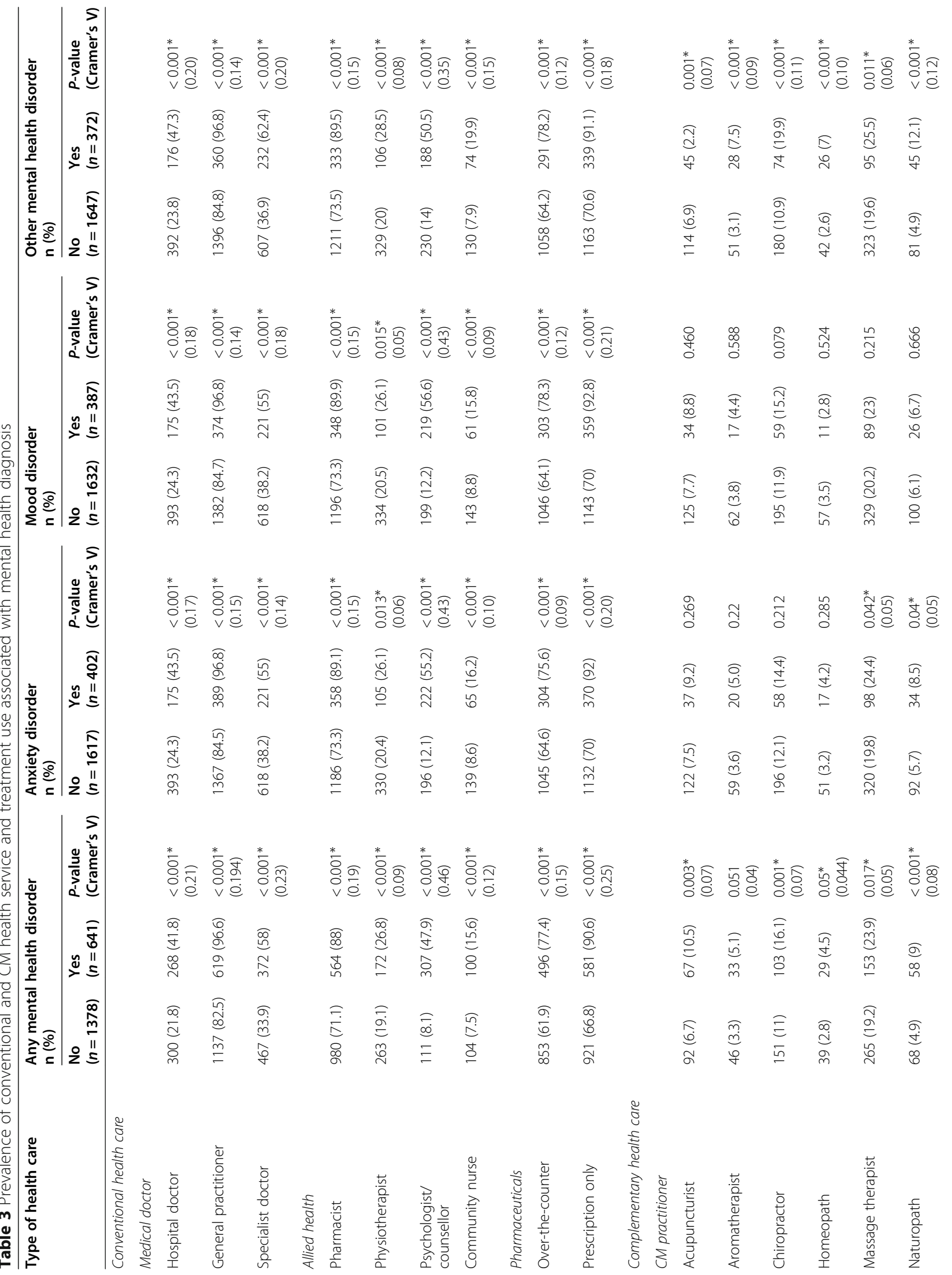




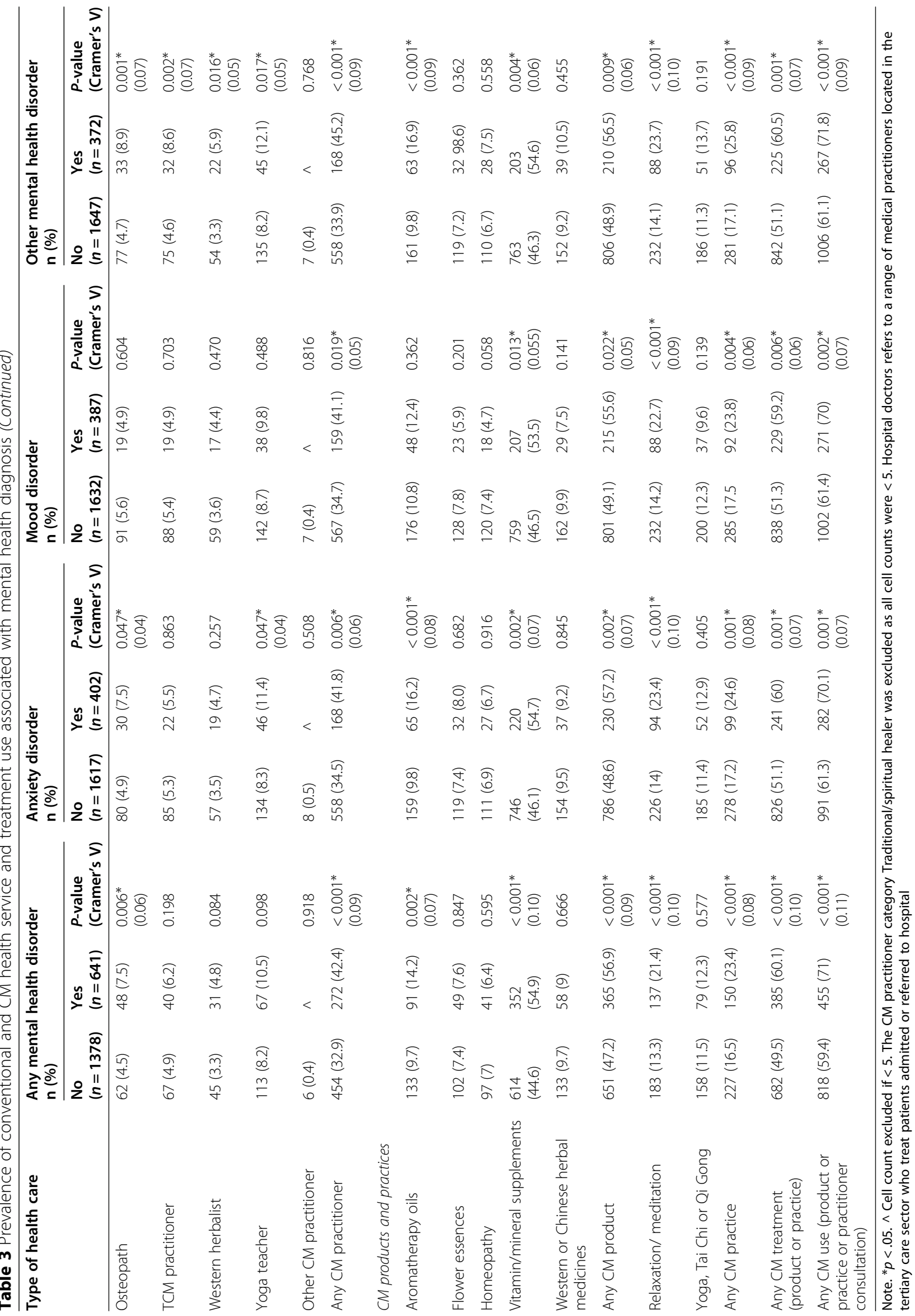


Table 4 Out-of-pocket expenditure on type of health service and treatment used in the previous 12 months

\begin{tabular}{|c|c|c|c|c|c|c|}
\hline \multirow{3}{*}{$\begin{array}{l}\text { Type of treatment show or } \\
\text { service used }\end{array}$} & \multirow{3}{*}{$\begin{array}{l}\text { Total annual expenses } \\
\text { MHD participants } \\
(n=641)\end{array}$} & \multirow{3}{*}{$\begin{array}{l}\text { Estimated total annual } \\
\text { expenses for Australian } \\
\text { population with a MHD } \\
\text { (AUD) } \\
(n=5,584,169.29)^{\mathrm{a}}\end{array}$} & \multicolumn{4}{|c|}{ Mean/median annual expense } \\
\hline & & & \multicolumn{2}{|c|}{$\begin{array}{l}\text { MHD participants } \\
(n=641)\end{array}$} & \multicolumn{2}{|c|}{$\begin{array}{l}\text { No-MHD participants } \\
(n=1378)\end{array}$} \\
\hline & & & Mean & Median & Mean & Median \\
\hline \multicolumn{7}{|l|}{ Pharmaceuticals } \\
\hline Prescription-only & 93,237 & $812,246,608$ & 145.46 & $30.00^{*}$ & 82.38 & $12.00^{*}$ \\
\hline Over-the-counter & 34,853 & $303,629,840$ & 54.37 & $20.00^{*}$ & 32.62 & $10.00^{*}$ \\
\hline Total & 128,090 & $1,115,876,448$ & 199.83 & 60.00 & 115.00 & 30.00 \\
\hline \multicolumn{7}{|l|}{ CM products } \\
\hline Vitamins/Mineral Supplements & 32,387 & $282,146,905$ & 50.53 & 5.00 & 40.57 & 0.00 \\
\hline Aromatherapy oils & 4,579 & $39,890,657$ & 7.14 & 0.00 & 4.21 & 0.00 \\
\hline Western/Chinese herbal medicine & 4,307 & $37,521,088$ & 6.72 & 0.00 & 5.24 & 0.00 \\
\hline Homeopathy & 4,058 & $35,351,886$ & 6.33 & 0.00 & 2.31 & 0.00 \\
\hline Flower Essences & 2,369 & $20,670,152$ & 3.70 & 0.00 & 1.99 & 0.00 \\
\hline Total & 47,580 & $415,580,687$ & 74.34 & 10.00 & 54.48 & 0.00 \\
\hline \multicolumn{7}{|l|}{ CHC practitioner } \\
\hline General practitioner & 203,829 & $1,775,687,082$ & 317.99 & 0.00 & 43.10 & 0.00 \\
\hline Specialist doctor & 89,775 & $782,086,866$ & 140.05 & $0.00^{*}$ & 111.52 & $0.00^{*}$ \\
\hline Hospital doctor & 47,855 & $416,896,133$ & 74.66 & $0.00^{*}$ & 17.88 & $0.00^{*}$ \\
\hline Counsellor/Psychologist & 38,287 & $333,543,042$ & 59.73 & $0.00^{*}$ & 11.08 & $0.00^{*}$ \\
\hline Community nurse & 2,825 & $24,610,418$ & 4.41 & 0.00 & 3.16 & 0.00 \\
\hline Physiotherapist & 13,725 & $119,567,431$ & 21.41 & 0.00 & 19.04 & 0.00 \\
\hline Total & 396,2956 & $3,452,390,973$ & 618.25 & 60.00 & 205.80 & 25.00 \\
\hline \multicolumn{7}{|l|}{ CM practitioner } \\
\hline Massage therapist & 17,853 & $155,772,147$ & 27.90 & 0.00 & 16.77 & 0.00 \\
\hline Chiropractor & 15,418 & $134,316,259$ & 24.05 & 0.00 & 12.57 & 0.00 \\
\hline Yoga teacher & 3,463 & $30,168,453$ & 5.40 & 0.00 & 4.74 & 0.00 \\
\hline Acupuncturist & 7,431 & $64,837,441$ & 11.61 & 0.00 & 5.13 & 0.00 \\
\hline Naturopath & 10,169 & $88,588,795$ & 15.86 & $0.00^{*}$ & 4.02 & $0.00^{*}$ \\
\hline Osteopath & 4,334 & $37,756,302$ & 6.76 & 0.00 & 3.99 & 0.00 \\
\hline TCM practitioner & 3,537 & $30,813,115$ & 5.52 & 0.00 & 4.07 & 0.00 \\
\hline Aromatherapist & 8,992 & $78,335,180$ & 14.03 & 0.00 & 2.10 & 0.00 \\
\hline Homeopath & 3,268 & $28,469,681$ & 5.10 & 0.00 & 3.36 & 0.00 \\
\hline Western Herbalist & 3,731 & $32,503,176$ & 5.82 & 0.00 & 2.77 & 0.00 \\
\hline Total & 70,532 & $681,560,548$ & 110.38 & 0.00 & 59.41 & 0.00 \\
\hline \multicolumn{7}{|l|}{ CM practices } \\
\hline Yoga/tai chi & 4,076 & $35,508,696$ & 6.36 & $0.00^{*}$ & 6.58 & $0.00^{*}$ \\
\hline $\begin{array}{l}\text { Relaxation/ } \\
\text { meditation }\end{array}$ & 5,866 & $51,102,554$ & 9.15 & 0.00 & 3.36 & 0.00 \\
\hline Total & 9,942 & $86,611,250$ & 15.51 & 0.00 & 9.95 & 0.00 \\
\hline
\end{tabular}

Note. AUD Australian dollars, MHD mental health disorder, $C H C$ conventional health care, $C M$ complementary medicine, $T C M$ traditional Chinese medicine. ${ }^{\text {a The }}$ estimated number of the Australian population with a MHD was calculated based on Australian census figures in year 2016 for Australian adults aged 20 years or above $(n=17,615,676)$ and the reported prevalence of mental health disorders in this study $(31.7 \%)$. Indicates a significant difference between median expenses of MHD and no-MHD groups $(p<.05)$

consultations $(p<.05)$. Age, qualification level, private health insurance, MHD and chronic physical illness significantly predicted $(p<.05)$ specialist doctor consultations. For psychologist/counsellor consultations, six predictor variables were statistically significant $(p<.05)$ : age, marital status, employment status, health 
Table 5 Hierarchical multiple regression predicting total health care expenses

\begin{tabular}{|c|c|c|c|c|c|c|}
\hline \multirow[b]{3}{*}{ Variable } & \multicolumn{6}{|c|}{ Total health care expenses } \\
\hline & \multicolumn{2}{|l|}{ Model 1} & \multicolumn{2}{|l|}{ Model 2} & \multicolumn{2}{|l|}{ Model 3} \\
\hline & B & ß & B & B & B & ß \\
\hline Constant & $1058.57^{* *}$ & & $947.58^{* *}$ & & $557.54^{*}$ & \\
\hline Gender & -44.28 & -0.02 & -26.49 & -0.01 & -4.91 & 0.00 \\
\hline Age & -3.04 & 0.00 & -28.13 & -0.04 & -16.31 & -0.02 \\
\hline ARIA+ & 14.96 & 0.01 & 11.24 & 0.01 & 12.88 & 0.01 \\
\hline Marital status & 18.79 & 0.02 & 15.70 & 0.02 & 9.65 & 0.01 \\
\hline Highest qualification & -24.08 & -0.02 & -25.55 & -0.03 & -26.49 & -0.03 \\
\hline Financial manageability & -1.40 & 0.00 & -0.64 & 0.00 & 25.00 & 0.02 \\
\hline Employment status & -22.80 & -0.04 & -32.53 & -0.05 & $-41.52^{*}$ & -0.07 \\
\hline Private health insurance & $-229.92^{* *}$ & -0.11 & $-215.56^{* *}$ & -0.10 & $-221.35^{* *}$ & -0.10 \\
\hline Health care card & -50.84 & -0.02 & -36.40 & -0.02 & -25.24 & -0.01 \\
\hline Chronic physical illness & & & $288.46^{* *}$ & 0.13 & $248.56^{* *}$ & 0.12 \\
\hline Mental health disorder & & & & & $244.56^{* *}$ & 0.11 \\
\hline$R^{2}$ & 0.012 & & 0.028 & & 0.038 & \\
\hline$F$ & $2.72^{*}$ & & $5.74^{* *}$ & & $7.11^{* *}$ & \\
\hline$\Delta R^{2}$ & $0.012^{*}$ & & $0.016^{* *}$ & & $0.010^{* *}$ & \\
\hline
\end{tabular}

Note. ${ }^{*} p<.05,{ }^{* *} p<.001 . \mathrm{B}=$ Unstandardised regression coefficient, $\beta=$ Standardised regression coefficient, $\Delta R^{2}=$ squared part correlations. The Australian health care card is a concessions card providing discounted medicines and services to eligible low income patients and is funded by the Australian Federal Government. ARIA is the Accessibility/Remoteness Index of Australia supported and utilised by the Commonwealth Dept of Health and the Australian Bureau of Statistics. ACT is the Australian Capital Territory

care card, MHD and chronic physical illness. CM practitioner consultations were significantly $(p<.05)$ predicted by gender, age, employment status, private health insurance, MHD, and chronic physical illness.

Males were less likely to see a general practitioner $(O R=0.666,95 \%$ CI $[0.490,0.905])$ or any CM practitioner than females $(O R=0.709,95 \%$ CI [0.573, $0.878]$ ). Being 50-59 years old was associated with an increased likelihood of consulting with a specialist doctor. In contrast, older people aged 50-59 and 60 and over were less likely to consult a $\mathrm{CM}$ practitioner $(O R=0.538,95 \%$ CI $[0.373,0.775] ; O R=0.398$, $95 \% \mathrm{CI}[0.273,0.581]$ respectively) or a psychologist/ counsellor $(O R=0.394,95 \%$ CI $[0.243,0.639]$; $O R=$ $0.267,95 \%$ CI $[0.160,0.447]$ respectively). Participants either in casual/temp work or looking for work were almost twice as likely to visit a psychologist or counsellor $(O R=1.812,95 \%$ CI $[1.088,3.017] ; O R=$ $1.886,95 \%$ CI $[1.156,3.078]$, respectively); similarly people either looking for work or not in the workforce were less likely to visit a $\mathrm{CM}$ practitioner $(O R=0.298,95 \%$ CI $[0.194,0.458] ; O R=0.476,95 \%$ CI $[0.353,0.642]$, respectively). People with a MHD or chronic physical illness were more likely to consult with any health practitioner compared to those without a MHD or chronic physical illness respectively.

\section{Predictors of type of health treatment use}

Table 7 summarises the results of the four logistic regression models predicting each type of health treatment used, which were statistically significant $(p<.001)$. Prescription pharmaceutical use was significantly $(p<.05)$ predicted by age, financial management, private health insurance, MHD and chronic physical illness. Gender, age, area of residence, private health insurance, MHD and chronic physical illness were significant predictors of OTC pharmaceutical use $(p<.05)$. Gender, qualification level, private health insurance MHD and chronic physical illness significantly predicted $\mathrm{CM}$ product use $(p<.05)$, whilst age, qualification level, health care card and MHD significantly predicted CM mind-body practice use $(p<.05)$.

Males were less likely to use OTC pharmaceuticals $(O R=0.739,95 \% \mathrm{CI}[0.600,0.910]), \mathrm{CM}$ products $(O R=$ $0.563,95 \%$ CI $[0.461,0.687])$ or prescription pharmaceuticals $(O R=0.791,95 \%$ CI $[0.610,1.010])$ than males. Those 60 and over were twice as likely to use prescription pharmaceuticals $(O R=2.04,95 \%$ CI $[1.307,3.182])$ than those in the youngest age group (18-29 years), while those in the 40-49 age group were more likely to use OTC pharmaceuticals $(O R=1.598,95 \%$ CI $[1.135$, 2.250]). In contrast, all older age groups were less likely to use CM mind-body practices compared to the youngest age group. Those who's financial management was 


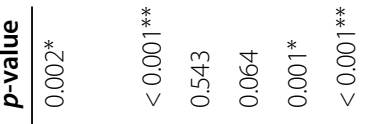

$\stackrel{\infty}{\infty} \underset{n}{\infty} \infty$

\begin{tabular}{lllll}
$\circ$ & 0 & 0 & $\overline{0}$ & \multirow{1}{*}{} \\
$\circ$ & 0 & 0 & 0 & 0 \\
0 & 0 & 0 & 0
\end{tabular}

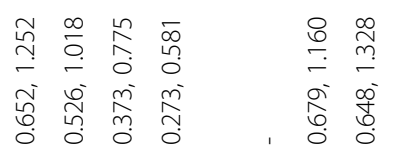

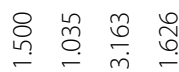

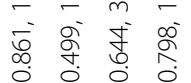

@.

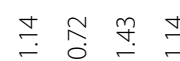

용

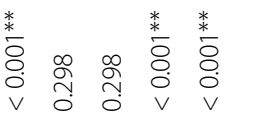

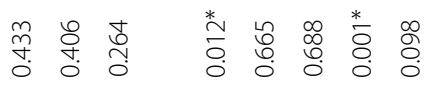

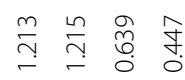

mi

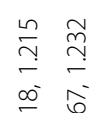

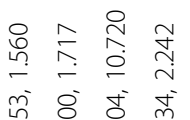

文

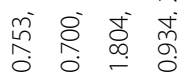

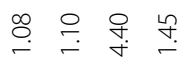

$\begin{array}{lll}\infty & 0 \\ 0 & \stackrel{0}{0} & \stackrel{0}{0} \\ 0 & 0\end{array}$

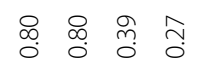

娄

总弪

$\overbrace{0}^{\infty} \delta$

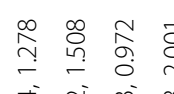

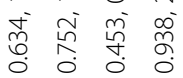

윧 ᄋ̊ 웅

$\begin{array}{lllll}0 & 1 & 0 & 0 \\ 0 & 0 & 0 & 0 \\ 0 & 0 & 0 & 0 & 0 \\ 0 & 0 & 0 & 0 & 0\end{array}$

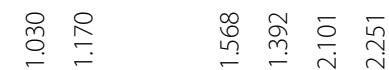

过

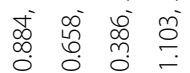

$\sum_{2}^{\circ}$

它

离

․ ㅇ. 우

$\stackrel{\substack{0 \\ 0}}{\infty}$

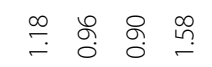

娄 $\stackrel{*}{8}$

胥

䓵

$\frac{0}{m}$

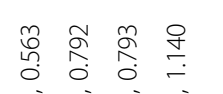

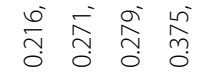

$\stackrel{\infty}{\circ} \underset{0}{0} \underset{0}{0}$

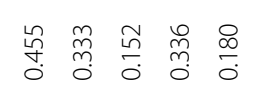

范点

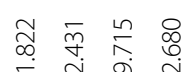

$\begin{array}{lll}\infty & 0 \\ \infty & \infty \\ \infty & 0 \\ 0 & 0\end{array}$

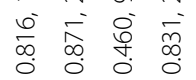

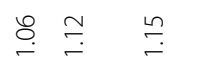

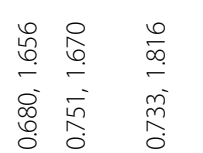

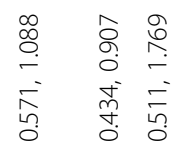

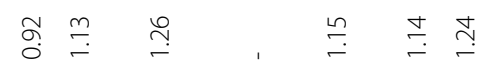

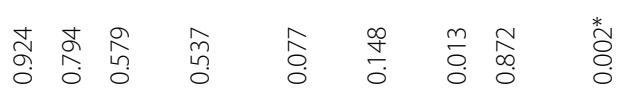

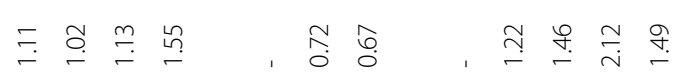

$\stackrel{n}{m} \stackrel{\stackrel{n}{m}}{\stackrel{\sim}{r}}$

$\begin{array}{llll}\infty & 0 & 0 \\ 0 & 0 & 0 & 0 \\ 0 & 0 & 0\end{array}$ 


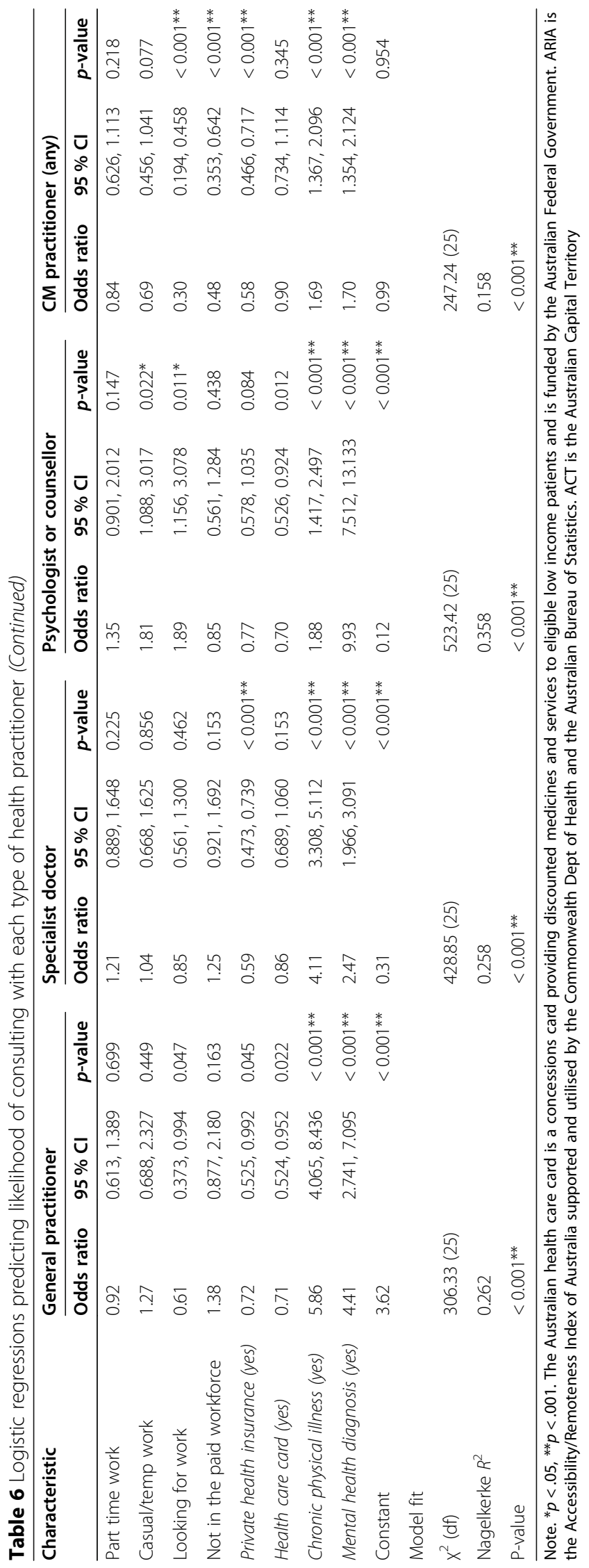




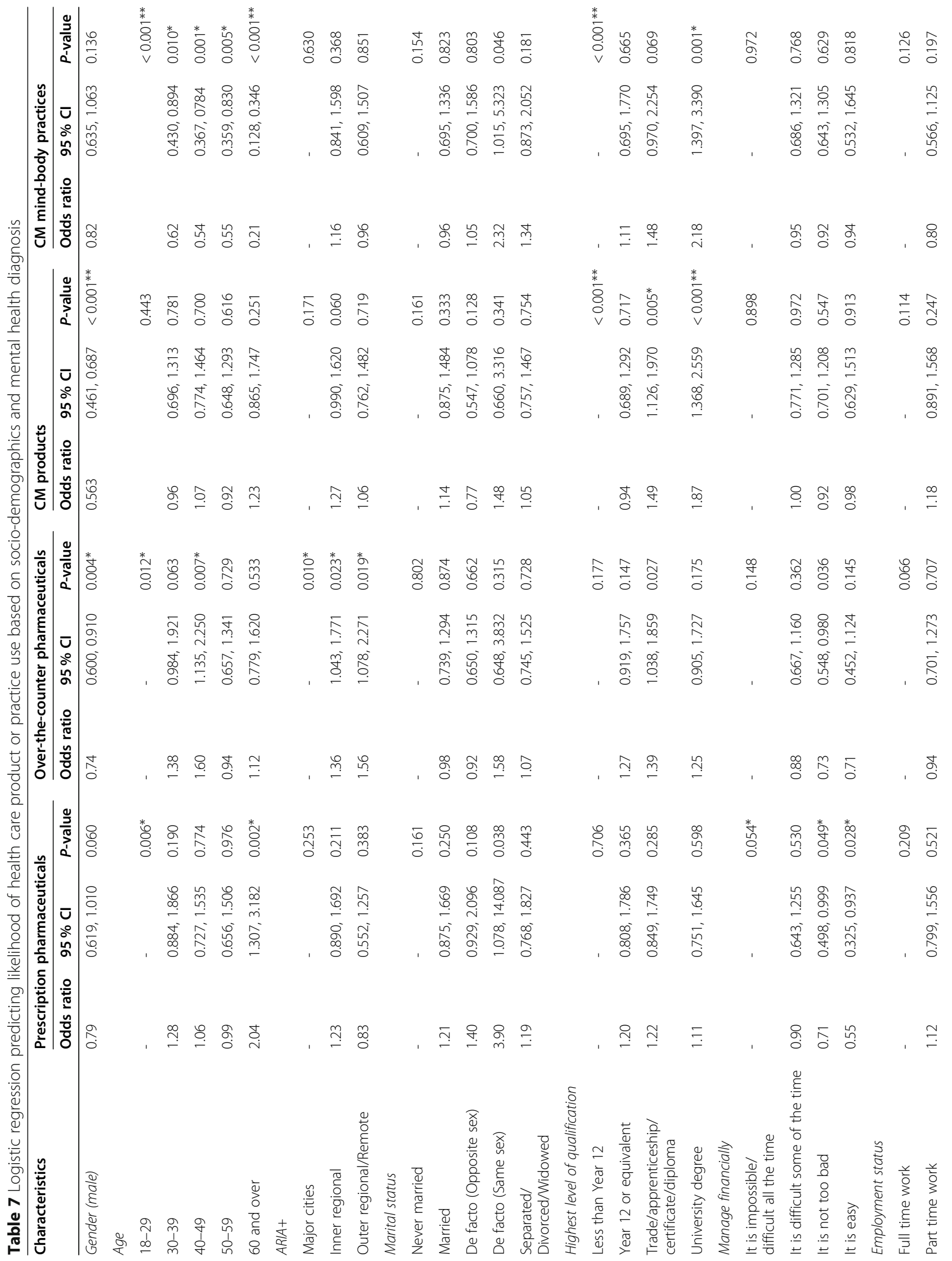




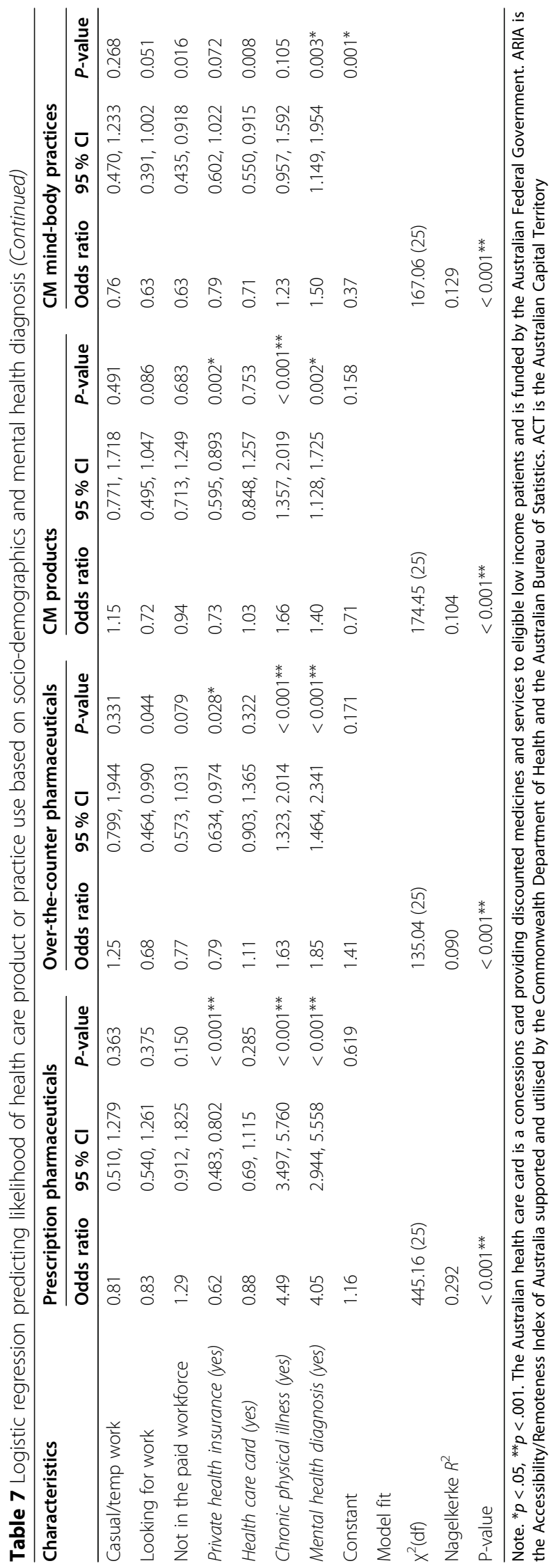


either "not too bad" or "easy", or had private health insurance were less likely to use prescription pharmaceuticals. Those with PHI were also less likely to use OTC pharmaceuticals or $\mathrm{CM}$ products, while those with a health care cared were less likely to use mind-body practices. As a participant's qualification level rose, the greater the likelihood of the participant reporting CM product or mind-body practice use. Those with a MHD were more likely to use any type of health treatment compared to those without a MHD, with prescription pharmaceuticals having the greatest increased odds of being used $(O R=4.045,95 \%$ CI $[2.944,5.558])$. People reporting a chronic physical illness were also more likely to use prescription or OTC pharmaceuticals or CM products, but not mind-body practices.

\section{Discussion}

This nationally representative study provides insights into the prevalence, sociodemographic, and healthrelated characteristics of Australian adults reporting a MHD. The findings also shed light on conventional and $\mathrm{CM}$ health care use, including OOP costs, in this population. Of significance is the identification of predictors of health care use and type of health practitioner or treatment use. Having an MHD diagnosis was an important predictor of all types of health care use. This is consistent with previous research indicating that people with a mental health condition are high users of conventional health care $[4,23]$ or CM health care [7].

In the current study, people with a MHD were more likely to use all types of conventional health care (i.e., doctors, allied health, prescribed pharmaceutical medicines, and OTC pharmaceutical medicines). When controlling for all other variables, having a MHD was the most important predictor of consultations with psychologists/counsellors (i.e., those with an MHD were more likely to consult with them) being almost ten times more likely to consult with them than those without a MHD. We also found that having a MHD was an important predictor of all types of ingestible medicine use. Of specific interest was the finding that people with a MHD were four times more likely than those without a MHD to be using a prescription pharmaceutical medicine. These results reflect similar findings from the APC Report [4], which found that people with a MHD were high users of primary health care practitioners, particularly general practitioners and psychologists, and high users of prescribed medication. The immediate concern with such prevalent use of both complementary and pharmaceutical medicines is the potential for medicine interactions or inappropriate medicine use. Importantly, the high prevalence of comorbid chronic conditions reported by people with a MHD is likely to be driving high medicines use and polypharmacy. This is consistent with our finding that those with a chronic physical condition were more likely than those without to use all types of medicines. Collectively, multiple conventional and complementary health care practitioners involved in the care of a person with a MHD and self-prescribing of CMs, coupled with poor interprofessional communication is likely to increase the potential for medicines interactions [24]. This further supports the need for a more coordinated approach to health service provision (including the prescribing of medicines) for people living with a MHD.

The findings from our study suggest mental health consumers are using $\mathrm{CM}$ health services for different needs. For example, we found that although having a mood disorder was associated with consulting with at least one type of $\mathrm{CM}$ practitioner, it was not associated with any specific type of CM practitioner; in contrast, those with an anxiety disorder diagnosis were more likely to consult with particular types of $\mathrm{CM}$ practitioners such as massage therapists. Results from previous studies investigating $\mathrm{CM}$ use for mental health conditions are mixed [8-10]. A lack of research on this topic, inconsistent research designs and heterogeneity of variables make it difficult to draw appropriate comparisons between the results obtained from the current study and that reported in other studies. Further research is needed to provide a clearer picture of how a specific MHD may or may not influence a patient's choice of CM health services.

Considerable investigation has been undertaken to understand how the needs of people with a mental illness can be met. Consultation with mental health services, practitioners and consumers, together with numerous government reports draw the same conclusionthe current needs of mental health consumers are not being met $[4,25,26]$. Similarly, these key stakeholders advocate for a redesign of primary health care service delivery, especially reduction of service fragmentation and a lack of seamlessness with other health care providers, whether at the practitioner or health service level. These discussions, including further research examining the merits of varying models of health care to address these unmet needs, are vital.

The results from this study show that Australians with a MHD were high users of CM and that this may be an attempt to fill, or be filling, an unmet need. Research examining the merits of integrative health care models within primary care (those that are clinically governed by a general practitioner who can act as a gatekeeper in regards to $\mathrm{CM}$ use and work collaboratively with $\mathrm{CM}$ practitioners or directly provide CM treatments) [2729 ], suggests that this model has a role to play in helping to address the current issues concerning mental health care [30-32]. To date, the role of CM practitioners as a mental health resource and their role in connection with 
existing conventional health care service provision has not been widely discussed. Not only is further research required to comprehensively evaluate the appropriateness of this health care model, but the known public health risks related to $\mathrm{CM}$ use and how best to respond to these risks also necessitates national deliberation. An example of this can be drawn from a key discussion contained in the APC Report regarding OOP costs.

The APC Report states "consumers can incur sizable out of pocket costs when accessing treatment" [4, pg. 150], which reflects the findings of our study as well as other reports $[5,11,33]$. The APC acknowledges that data concerning OOP costs for consumers is limited. Furthermore, these reports do not include $\mathrm{CM}$ use. Accounting for the impact of CM use on OOP costs can be a complicated matter, as rebate funding via either the public (Medicare) or private systems (private health insurance) or a consumers socioeconomic status (SES; i.e., discretionary spending capacity) can have a differential impact on the decision-making process regarding choice of health care services or treatments, and in turn, overall OOP costs $[6,34]$. The cost of mental health care is known to be a factor in help-seeking, obtaining treatment and support in both the short and longer term, and is correlated with subsequent mental or physical health status [35].

The results of our study found that, in general, those with a MHD did not spend more on CM. Potential reasons for this may be the absence or presence of Medicare or private health insurance rebates, or the SES of the consumer, but other factors also could be at play. Such factors may include the influence of health literacy level, personal ideology or close peers on health care choices. Our findings highlight important omissions from the current national mental health care discourse related to economic factors. These include a high amount of mental health consumer spending on CM services, practices or products that may or may not be evidence-based, as well as a perceived benefit of CM by the consumer. These are important considerations as financial decisions about health care may result in delays in help-seeking, treatment and diagnosis. More needs to be understood about the economic factors driving both conventional and CM health care choices and how OOP costs ultimately impact mental health outcomes.

Our study has several limitations that should be considered when interpreting our results. The study may be vulnerable to random error due to sampling bias; however, as the participants were nationally consistent based on gender and age [13], this is likely to have minimal impact on the outcome of our analyses. As this was an online study it may not adequately represent Aboriginal and Torres Strait Islander peoples and other population groups who have less access to the Internet. Recall bias is a possibility given the self-reported nature of the study, and the 12-month timeframe of many questions. Participant's mental health diagnosis was also susceptible to self-report without a confirmatory diagnosis by a qualified health professional; consequently, the data is vulnerable to detection bias. In addition, the selfreported mental health diagnosis relies upon the individual being aware of a mental health condition and seeking care, and the health care capacity being in place to diagnose mental health disorders. Consequentially, the study is likely to underestimate the real mental health problem and related expenditures in the population studied. Finally, identifying the income of the study participants and collecting data on the resident to provider ratio (possibly important in accessing care) would both have provided useful additional insights to the analysis but unfortunately such information was not collected in the study.

The increasing prevalence of MHD and associated CM use in Australia warrants closer examination. The public health implications of $\mathrm{CM}$ use among mental health consumers requires national discussion with a diverse range of key stakeholders to ensure there is an appropriate response at the health care service level, right through to policy. Current research examining the redesign of primary health care provision should also consider whether CM practitioners and/or integrative health care service delivery models could play a role in addressing known risks associated with $\mathrm{CM}$ use and the unmet needs of people living with an MHD.

\section{Abbreviations}

APC: Australian Productivity Commission; CM: complementary medicine; MHD: mental health disorder; OOP: out-of-pocket

\section{Acknowledgements}

Not applicable.

\section{Authors' contributions}

EM, AS and JH were responsible for conceptualising the study, design of methodology, investigation and project administration. AS and EM were responsible for funding acquisition. EM was responsible for data management and analysis. AS assisted with the economic analysis. TO and EM were responsible for interpreting the data. TO, EM, AS, JH and ML were major contributors in writing the manuscript. JA critically reviewed and edited the manuscript in addition to providing mentorship to the core research team throughout the project. All authors read and approved the final manuscript.

\section{Funding}

This research was supported by funding from Endeavour College of Natural Health and the Australian Research Centre in Complementary and Integrative Medicine (University of Technology Sydney). TO was supported by an Australian Government Research Training Program Scholarship while working on this manuscript. JA was supported by an Australian Research Council Professorial Future Fellowship while working on this manuscript (Grant FT140100195). JH's academic position was supported by a philanthropic donation from Blackmores Pty Ltd during the course of this study.

Availability of data and materials

The datasets used and/or analysed during the current study are available from the corresponding author on reasonable request. 


\section{Declarations}

\section{Ethics approval and consent to participate}

The Human Research Ethics Committee at Endeavour College of Natural Health provided ethics approval (20170242) in accordance with the National Health and Medical Research Council Statement on Ethical Conduct in Human Research. Charles Sturt University (H17048), The University of Sydney (2017/140) and The University of Technology Sydney (ETH17-1564) Human Research Ethics Committees also granted ethics approval. All methods were conducted in accordance with the National Statement on Ethical Conduct in Human Research [36].

\section{Consent for publication}

Not applicable.

\section{Competing interests}

The authors declare that they have no competing interests.

\section{Author details}

'Australian Research Centre in Complementary and Integrative Medicine, School of Public Health, Faculty of Health, University of Technology Sydney, 2007 Ultimo, NSW, Australia. ${ }^{2}$ Institute for Sustainable Futures, University of Technology Sydney, PO Box 123, 2007 Ultimo, NSW, Australia. ${ }^{3}$ National Centre for Naturopathic Medicine, Southern Cross University, NSW 2480 Lismore, Australia. ${ }^{4}$ Faculty of Medicine and Health, The University of Sydney School of Pharmacy, 2006 Sydney, NSW, Australia.

Received: 20 March 2021 Accepted: 1 October 2021

Published online: 23 November 2021

\section{References}

1. Australian Bureau of Statistics: National Health Survey: First results. In. Canberra: Australian Bureau of Statistics; 2018.

2. Auerbach RP, Mortier P, Bruffaerts R, Alonso J, Benjet C, Cuijpers P, Demyttenaere K, Ebert DD, Green JG, Hasking P et al: WHO World Mental Health Surveys International College Student Project: Prevalence and distribution of mental disorders. J Abnorm Psychol 2018, 127(7):623-638.

3. Vigo D, Thornicroft $G$, Atun R: Estimating the true global burden of mental illness. Lancet Psychiatry 2016, 3(2):171-178

4. Productivity Commission: Mental Health. In., vol. Report no. 95. Canberra: Productivity Commission; 2020

5. Russell L, Doggett J: A road map for tackling out-of-pocket health care costs. In. Australia; 2019.

6. Spinks J, Hollingsworth B: Policy implications of complementary and alternative medicine use in Australia: Data from the National Health Survey. J Altern Complement Med 2012, 18(4):371-378.

7. Reid R, Steel A, Wardle J, Trubody A, Adams J: Complementary medicine use by the Australian population: a critical mixed studies systematic review of utilisation, perceptions and factors associated with use. BMC Complement Altern Med 2016, 16:176

8. McIntyre E, Saliba AJ, Wiener KKK, Sarris J: Prevalence and predictors of herbal medicine use in adults experiencing anxiety: A critical review of the literature. Adv Integr Med 2015, 2(1):38-48.

9. Solomon D, Adams J: The use of complementary and alternative medicine in adults with depressive disorders. A critical integrative review. J Affect Disord 2015, 179:101-113.

10. McIntyre E, Saliba AJ, Wiener KK, Sarris J: Herbal medicine use behaviour in Australian adults who experience anxiety: A descriptive study. BMC Complement Altern Med 2016, 16:60.

11. Zurich Australia: The cost of care: The missing link in the strategic financial advice equation. In. Australia: Zurich Australia Limited; 2018: 92-105.

12. Von Conrady DM, Bonney A: Patterns of complementary and alternative medicine use and health literacy in general practice patients in urban and regional Australia. Aust Fam Physician 2017, 46(5):315-320.

13. Steel A, Mclntyre E, Harnett J, Foley H, Adams J, Sibbritt D, Wardle J, Frawley J: Complementary medicine use in the Australian population: Results of a nationally-representative cross-sectional survey. Scientific Reports 2018, 8(1):1-7.

14. 2016 Census QuickStats [https://quickstats.censusdata.abs.gov.au/census services/getproduct/census/2016/quickstat/0]
15. Hays RD, Sherbourne CD, Mazel RM: User's Manual for the Medical Outcomes Study (MOS) Core Measures of Health-Related Quality of Life. Santa Monica, CA: RAND; 1995.

16. Quandt SA, Verhoef MJ, Arcury TA, Lewith GT, Steinsbekk A, Kristoffersen AE, Wahner-Roedler DL, Fonnebo V: Development of an international questionnaire to measure use of complementary and alternative medicine (I-CAM-Q). J Altern Complement Med 2009, 15(4):331-339.

17. Quandt SA, Ip EH, Saldana S, Arcury TA: Comparing two questionnaires for eliciting CAM use in a multi-ethnic US population of older adults. Eur J Integr Med 2012, 4(2):e205-e211.

18. Bryden GM, Browne M: Development and evaluation of the R-I-CAM-Q as a brief summative measure of CAM utilisation. Complement Ther Med 2016, 27:82-86.

19. Lemeshow S, Sturdivant RX, Hosmer DW: Chap. 4: Model-Building Strategies and Methods for Logistic Regression. In: Applied Logistic Regression. New York, US: John Wiley \& Sons, Incorporated; 2013.

20. Australian Bureau of Statistics: Catalogue No. 3101.0 - Australian Demographic Statistics, Population by age and sex, June 2016. In.; 2017.

21. Stewart AL, Hays RD, Ware JE: The MOS Short-form General Health Survey. Medical Care 1988, 26(7):724-735.

22. Cuijpers $P$, Smits $N$, Donker $T$, ten Have $M$, de Graaf R: Screening for mood and anxiety disorders with the five-item, the three-item, and the two-item Mental Health Inventory. Psychiatry Res 2009, 168(3):250-255.

23. Royal Australian College of General Practitioners: General Practice: Health of the Nation Report. In. Melbourne, Vic.: RACGP; 2019.

24. Nguyen J, Smith L, Hunter J, Harnett JE: Conventional and complementary medicine health care practitioners' perspectives on interprofessional communication: A qualitative rapid review. Medicina 2019, 55(10).

25. National Mental Health Commission: Monitoring mental health and suicide prevention reform: National report 2019. 2019.

26. Australian Health Ministers' Advisory Council: National Strategic Framework for Chronic Conditions. In. Canberra: Australian Government; 2017.

27. Leach MJ, Eaton H, Agnew T, Thakkar M, Wiese M: The effectiveness of integrative healthcare for chronic disease: A systematic review. Int J Clin Pract 2019, 73(4):e13321

28. Leach MJ, Wiese M, Agnew T, Thakkar M: Health consumer and health provider preferences for an integrative healthcare service delivery model: A national cross-sectional study. Int J Clin Pract 2018, 72(6):e13204.

29. Grace S, Higgs J: Integrative medicine: Enhancing quality in primary health care. J Altern Complement Med 2010, 16(9):945-950.

30. Sarris J, Glick R, Hoenders R, Duffy J, Lake J: Integrative mental healthcare White Paper: Establishing a new paradigm through research, education, and clinical guidelines. Adv Integr Med 2014, 1(1):9-16.

31. Lake J, Helgason C, Sarris J: Integrative Mental Health (IMH): paradigm, research, and clinical practice. Explore (NY) 2012, 8(1):50-57.

32. Glick RM: Integrative mental health in 2015. Adv Integr Med 2015, 2(1):1-2.

33. Royal Australian and New Zealand College of Psychiatrists (RANZCP): Minding the gaps: Cost barriers to accessing health care for people with mental illness. In. New Zealand; 2015.

34. Callander E, Larkins S, Corscadden L: Variations in out-of-pocket costs for primary care services across Australia: A regional analysis. Aust J Prim Health 2017, 23(4):379-385

35. Callander EJ, Corscadden L, Levesque J-F: Out-of-pocket healthcare expenditure and chronic disease - do Australians forgo care because of the cost? Aust J Prim Health 2017, 23(1):15-22.

36. The National Health and Medical Research Council: National Statement on Ethical Conduct in Human Research. In. Canberra: Commonwealth of Australia; 2007.

\section{Publisher's Note}

Springer Nature remains neutral with regard to jurisdictional claims in published maps and institutional affiliations. 